\title{
SEMANTIC CONDITIONING INVOLVING THE GALVANIC SKIN REFLEX
}

\author{
BY BERNARD F. RIESS \\ Hunser College of the City of New York
}

In a recent issue of Science, Razran ${ }^{1}$ described the application of his salivary conditioning technique to the field of semantics. He reported success in transferring conditioned salivation from four words to a homophone and to a synonym for each of the original stimuli. In concluding the article, Razran mentioned the possibility of employing the galvanic skin reflex (GSR) as a substitute for the salivary technique. The present paper reports an initial investigation in which the words used by Razran formed the basis for a transferred conditioned response involving involuntary changes in skin resistance.

The GSR's were obtained by means of an instrument devised by F. C. Thorne in which a bucking circuit is employed to measure the changes in resistance of the subject. The amplitude of the reflex is measured in terms of microamperes. Metal electrodes were inserted in beakers filled with water into which the forefinger and the second digit of the subject's left hand were thrust. The fingers were wrapped in scotch cellulose tape for a predetermined distance in order to equalize the amount of skin exposed and to prevent shifts in resistance due to up and down movements of the fingers in the electrolyte. The stimulus words were typewritten on library cards and presented manually to the subject who was seated in a position from which the face of the instrument was not visible. Each card was exposed for five seconds during which the experimenter recorded the amplitude of the galvanic skin reaction.

The actual procedure consisted of three steps. In the first, each subject was presented with $5^{\circ}$ stimulus words, ex-

1 Ruzran, G. H. S., A quantitative study of meaning by a conditioned salivary technique (sementic conditioning). Science, 1939, 90, 89-90.

238 
posed seriatim. Of these words, four were later to be conditioned to the sound of a loud buzzer. A homophone and a synonym for each of the four major stimuli was included in the list. The GSR's for each word were recorded. The purpose behind this step was to determine the extent of the reaction to the words prior to the conditioning process.

At the next experimental session, the combination of buzzer and stimulus-word was begun. Each subject was presented with the reinforced stimulus for four trials during each session. At the end of each day's trials, one presentation of the stimulus-word alone was made to determine whether conditioning had taken place. Experimentation continued until the stimulus-word alone produced a GSR of at least three times the amplitude of the reaction prior to conditioning, on three out of four successive trials.

Immediately following upon the attainment of the criterion, the homophone and the synonym for each conditioned word were presented five times each in random order. The GSR's for these trials were then averaged for each type of word separately. Table I gives the results for all the subjects tested. The number of subjects varies from one set of words to another because some dropped out as a result of the pressure of college work. The subjects were students at Hunter College, all women and in the senior and junior years. None was familiar with the instrument used nor aware of the purpose of the experiment.

All GSR's in the table are expressed in microamperes. Each entry in the post-conditioning column represents the mean of four determinations for each of the subjects in the various parts of the experiment. That is, in the first group of words, each entry represents the mean of sixteen observations and in the second group, of 24 determinations.

Despite the small number of subjects and the variation from one set of words to another, several conclusions seem tenable. The galvanic skin reflex proved amenable to verbal conditioning. Furthermore, with the exception of the first group of words, there is evidence of transference. As in the case of Razran's experiment, the carry-over to the synonym 
TABLE I

Galvanic Skin Reylexps Conditioned to Four Words and to a Hoxophone AND SYNoNYM FOR EACH

\begin{tabular}{l|c|c|c|c}
\hline \hline Words & $\begin{array}{c}\text { No. of } \\
\text { subjects }\end{array}$ & $\begin{array}{c}\text { Pre-cond. } \\
\text { GSR's }\end{array}$ & $\begin{array}{c}\text { Post-cond. } \\
\text { GSR's }\end{array}$ & $\begin{array}{c}\text { Percentage gained } \\
\text { from conditioning }\end{array}$ \\
\hline Style & 4 & 30 & 220 & $633 \%$ \\
stile & 4 & 15 & 20 & 33 \\
fashion & & 60 & 80 & 33 \\
Freeze & 6 & 75 & 225 & 220 \\
frieze & & 25 & 60 & 140 \\
chill & & 80 & 232 & 190 \\
Surf & 7 & 100 & 355 & 255 \\
serf & & 45 & 80 & 76 \\
wave & & 55 & 136 & 147 \\
Urn & & 125 & 460 & 276 \\
earn & 9 & 135 & 310 & 129 \\
vase & & 90 & 265 & 194 \\
\hline
\end{tabular}

Mean gain in percentages for each type of word

Stimulus words. ................... $346.0 \%$

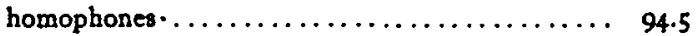

synonyms...................... 141.0

All GSR's are given in terms of microamperes.

was consistently greater than to the homophone. In both experiments, then, transposal of a conditioned reaction is easier when the verbal stimuli are meaningfully linked than when they are merely like sounding. From these preliminary results, it is apparent that the galvanic skin reflex offers a fertile field for experimentation in semantic conditioning. Research in progress at the moment indicates that a great deal of the variability in the pre-conditioning series may be eliminated by presenting the stimuli on lantern slides or film. In this way, the disturbance occasioned by the movements of the experimenter in presenting the cards will be eliminated. Another innovation that is being studied is the concealment of the connection between the words and the galvanic response. The subject is led to believe that response to shock is being studied and concentrates her attention upon the identification of a minimal shock stimulus rather than upon the reading of a specific word. This results in a loss in the magnitude of the original reflex. 